\title{
LIFESTYLE DETERMINANTS OF HEALTHY AGEING IN A MEDITERRANEAN POPULATION: THE MULTINATIONAL MEDIS STUDY
}

Alexandra Foscolou ${ }^{1}$, Emmanuella Magriplis ${ }^{1}$, Stefanos Tyrovolas ${ }^{1,2}$, George Soulis ${ }^{1}$, Vassiliki Bountziouka ${ }^{1}$, Anargiros Mariolis ${ }^{3}$, Suzanne Piscopo ${ }^{4}$, Giuseppe Valacchi ${ }^{5}$, Foteini Anastasiou ${ }^{6}$, Efthimios Gotsis ${ }^{1}$, George Metallinos ${ }^{1}$, Dimitra Tyrovola ${ }^{1}$, Anna Polystipioti ${ }^{1}$, Evangelos Polychronopoulos ${ }^{1}$, Antonia - Leda Matalas ${ }^{1}$, Christos Lionis ${ }^{6}$, Akis Zeimbekis ${ }^{7}$, Josep-Antoni Tur ${ }^{8}$, Labros S. Sidossis ${ }^{9}$, Demosthenes Panagiotakos ${ }^{1,9}$; for the MEDIS Study Group.

\begin{abstract}
${ }^{1}$ Department of Nutrition and Dietetics, School of Health Science and Education, Harokopio University, Athens, Greece; ${ }^{2}$ Parc Sanitari Sant Joan de Déu, Fundació Sant Joan de Déu, CIBERSAM, Universitat de Barcelona, Barcelona, Spain; ${ }^{3}$ Health Center of Areopolis, General Hospital of Sparta, Aeropolis, Greece; ${ }^{4}$ University of Malta, Nutrition, Family and Consumer Studies Office, Msida, Republic of Malta; ${ }^{5}$ Department of Life Sciences and Biotechnology, University of Ferrara, Ferrara, Italy; ${ }^{6} \mathrm{Clinic}$ of Social and Family Medicine, School of Medicine, University of Crete, Heraklion, Greece; ${ }^{7}$ Health Center of Kalloni, General Hospital of Mitilini, Mitilini, Greece; ${ }^{8}$ Research Group on Community Nutrition and Oxidative Stress, Universitat de les Illes Balears \& CIBERobn, Guillem Colom BIdg, Campus, E-07122 Palma de Mallorca, Spain; ${ }^{9}$ Department of Kinesiology and Health, School of Arts and Sciences, Rutgers University, NJ, USA
\end{abstract}

Address for Correspondence

Prof. Demosthenes B. Panagiotakos

46 Paleon Polemiston St., Glyfada, 166 74, Attica, Greece

Tel. +30210-9603116 \& Fax. +30210-9600719

E-mail: d.b.Panagiotakos@usa.net

\begin{abstract}
Background: To evaluate modifiable, lifestyle risk factors of cardiovascular disease (CVD) among older adults, across ageing, in the Mediterranean area. Methods: During 2005-2017, 3,131 individuals from 26 Mediterranean islands of 5 countries, $\geq 65$ years of age, were voluntarily enrolled. Anthropometrical, clinical and sociodemographic characteristics, dietary habits, lifestyle parameters were measured through standard procedures. Analyses were performed by year and across consecutive age groups of the participants. Results: A decrease in the prevalence of current smoking $(p<0.001)$, engagement in physical activities $(p=0.001)$ and participation in social events $(p=0.001)$ for every year increase in age was found. Moderate alcohol drinking increased through aging $(p=0.008)$, whereas adherence to Mediterranean diet remained stable, but adequate $(p=0.90)$. Trend analysis also revealed that a quadratic (U-shape) function better characterized the association between aging and total cardiometabolic risk factors burden ( $p$ for trend $<0.001$ ). Conclusions: The gaps in the understanding of factors affecting longevity and healthy ageing remain; public health authorities and stakeholders should focus on the lifestyle determinants of healthy ageing, that seems to be an effective mean for improving older peoples' health. Keywords: healthy ageing, longevity, elderly, health policy, Mediterranean.
\end{abstract}

\section{Introduction}

The population growth around the world is increasing rapidly. In 2015, people over 65 years of age represented $8.5 \%$ of the world's population, whereas by 2050 this percentage is expected to have doubled (He, Goodkind, \& Kowal, 2016). This demographic change is attributed to the increase in life expectancy, due to medical care attainments the past decades, effectiveness of public health strategies, as well as improvements in food quality, food safety and living conditions (Van De Kaa, 1987). Europe is currently facing one of the biggest challenges, which is to adapt European Union (EU) policies and strategies to meet the demands associated with this demographic change and assure healthy ageing (Courtin, Jemiai, \& Mossialos, 2014). In order, however to achieve healthy ageing it is necessary to identify and understand determinants of health and disease, as well as disease risk factors over time (Courtin et al., 2014). People have different ageing pathways, as per their genetic profile, as well as due to different life course health risk exposures (Tosato, Zamboni, Ferrini, \& Cesari, 2007). Ageing is associated with various lifestyle factors and early age exposures, and by the constantly changing nature and timing of these (Tosato et al., 2007). Furthermore, people's accessibility to health care services (Tyrovolas et al., 2011), nutrition quality, smoking status (regular or passive smoking), level of physical activity, anxiety \& social life status, may also affect ageing over time (Passarino, De Rango, \& Montesanto, 2016; Shadyab \& LaCroix, 2015). Ageing, and more specifically healthy ageing, is largely determined by individual lifestyle choices and not so by genetic inheritance (Passarino et al., 2016). The interactive effects, therefore of exposures and health states or diseases over time requires assessment.

Mediterranean people have always had the "privilege" of living in a health-friendly environment, as climate and general conditions have tended people to adopt healthy living standards and avoid stressful factors (Bach-Faig et al., 2011, p.; Chrysohoou et al., 2016). Therefore, and under the context of the MEDIS study (Tyrovolas et al., 2014), the aim of the present work was primarily to evaluate modifiable cardiovascular disease (CVD) lifestyle risk factors among older adults, across ageing, in the Mediterranean area; secondarily to evaluate the prevalence of cardiometabolic disorders and lifestyle characteristics across the course of aging. 


\section{Material and Methods}

The Mediterranean Islands (MEDIS) study is an ongoing, large-scale, multinational observational project held in the Mediterranean region, which aims to explore the association of lifestyle habits, psycho-social characteristics and living environment, on cardiometabolic factors, among older people ( $>65$ years), permanent residents of the Mediterranean area (Tyrovolas et al., 2014).

\subsection{The MEDIS study's sampling procedures}

During 2005-2017, a population-based, multi-stage sampling scheme (i.e., stratified by island, and sex distribution of the referent population according to census 2001) was applied to voluntarily enroll 3,131 men and women, over 65 years old, from 26 Mediterranean islands of 5 countries (i.e., Malta Republic $(n=250)$, Sardinia $(n=60)$ and Sicily $(n=50)$ in Italy, Republic of Cyprus $(n=300)$, Mallorca and Minorca $(n=111)$ in Spain, Gökçeada $(n=55)$ in Turkey and the Greek islands of Lesvos $(n=142)$, Samothraki $(n=100)$, Cephalonia $(n=115)$, Crete $(n=131)$, Corfu $(n=149)$, Limnos ( $n=150)$, Ikaria $(n=76)$, Syros $(n=151)$, Naxos $(n=145)$, Zakynthos $(n=103)$, Salamina $(n=147)$, Kassos $(n=52)$, Rhodes and Karpathos $(n=149)$, Tinos $(n=129)$, Ai Stratis $(n=30)$, Spetses $(n=92)$, Aegina $(n=59)$, Paros $(n=90)$ as well as the rural region of east Mani $(n=295)$. Inclusion criteria consisted of free-living participants, permanently residing on the islands and being over 65 years old. An attempt to include participants from various villages of each island was made in order to increase representativeness. Participants were enrolled on a feasibility basis. Exclusion criteria consisted of individuals who resided in assisted-living centers, had a clinical history of cardiovascular disease (CVD) or cancer, or had left the island for a considerable period of time during their life (i.e., $>5$ years), since the study aimed to assess lifestyle patterns that were not subject to modifications due to existing chronic health conditions or by environmental factors other than the immediate living milieu.

A group of experienced health scientists (physicians, dietitians, public health nutritionists and nurses) collected the required information through personal interviews and using standard procedures and validated questionnaires.

\subsection{Bioethics}

The study followed the ethical recommendations of the World Medical Association (52 ${ }^{\text {nd }}$ WMA General Assembly, Edinburgh, Scotland, October 2000). The Institutional Ethics Board of Harokopio University approved the study design (16/19-12-2006). Participants were informed about the aims and procedures of the study and gave their written consent prior to the interview.

\subsection{Evaluation of socio-demographic and lifestyle characteristics and health care services}

Basic socio-demographic characteristics such as age, sex, as well as lifestyle, such as smoking habits, physical activity status, number of friends and living status were also recorded. Current smokers were defined as those who smoked cigarettes or any type of tobacco at the time of the interview. Former smokers were defined as those who previously smoked, but had not done so for a year or more. Current and former smokers were further classified as ever smokers. The remaining participants were classified as non-smokers. Physical activity was evaluated in MET-minutes per week, using the short, translated and validated into Greek, version of the selfreported International Physical Activity Questionnaire (IPAQ) (Papathanasiou et al., 2009). Individuals who had at least 3 MET-minutes were defined "adequate physically active". The "number of friends" declared by respondents was based on their perception of how many friends they reported at the time of the interview, whereas "living status" was based on whether they live alone or not at the time of the interview. Participants who engaged in social events (e.g., going out with friends or relatives, participating in social activities) at least once a week over the last 12 months were characterized as "socialized". The presence of small physicians' offices, health care centers, or hospitals in the area of living, and the annual number of visits for regular health status check-ups, during winter and summer, by the participants were recorded. In addition, individuals were asked to declare if economic reasons that affect the visits to health care services were existed.

\subsection{Dietary assessment}

A validated food frequency questionnaire (FFQ) was used in the study's participants to capture their dietary habits (Tyrovolas, Pounis, Bountziouka, Polychronopoulos, \& Panagiotakos, 2010). To evaluate the level of adherence to the Mediterranean diet, the MedDietScore (range 0-55) was used (Panagiotakos, Pitsavos, \& Stefanadis, 2006). Higher MedDietScore indicate greater adherence to the Mediterranean diet and better quality in terms of health (a threshold of 35 - the median value - was used to categorize participants as closer to the traditional dietary pattern). Furthermore, consumption of various alcoholic drinks was measured in terms of wineglasses per day, adjusted for ethanol intake (e.g. one $100 \mathrm{~mL}$ glass of wine was considered to have $12 \%$ ethanol) and classified into never/rare (i.e., no alcohol drinking) or 1 to 2 glasses per day (moderate consumption) and to more than 2 glasses per day.

\subsection{Evaluation of clinical characteristics}

All measurements performed in the study's centres were standardized; a common questionnaire, translated to the language of each country, following the World Health Organization (WHO) translation guidelines for tools assessment, was administrated (WHO, n.d.). Weight and height were measured using standard procedures to attain body mass index (BMI) scores $\left(\mathrm{kg} / \mathrm{m}^{2}\right)$. Obesity was defined as $\mathrm{BMI}>29.9 \mathrm{~kg} / \mathrm{m}^{2}$. Type 2 Diabetes mellitus was determined by measuring fasting plasma glucose and values were used in 
accordance with the American Diabetes Association diagnostic criteria (fasting blood glucose levels $\geq 126 \mathrm{mg} / \mathrm{dl}$ or use of special antidiabetic medication) (Alberti \& Zimmet, 1998). Blood pressure was measured by trained physicians or nurses with participants in a sitting position and calm. An average of the 3 measurements was calculated. Participants who had blood pressure levels $>140 / 90 \mathrm{mmHg}$ or used antihypertensive medications were classified as hypertensive (Mancia et al., 2013). Fasting blood lipids levels were also recorded and hypercholesterolemia was defined as total serum cholesterol levels $>200 \mathrm{mg} / \mathrm{dL}$ or the use of lipid-lowering agents according to the NCEP ATPIII guidelines (Expert Panel on Detection, Evaluation, and Treatment of High Blood Cholesterol in Adults, 2001). The coefficient of variation for the blood measurements was less than $5 \%$. A cumulative variable (range $0-4$ ) indicating the overall burden of classical cardiometabolic risk factors (i.e., obesity and hypertension, diabetes and hypercholesterolemia) was developed (participants having none of the aforementioned risk factors received score 0 , having one factor score 1 , etc.).

Further details about the MEDIS study protocol are published elsewhere (Tyrovolas et al., 2009, 2014).

\subsection{Statistical analysis}

Continuous variables are presented as mean \pm standard deviation (SD) and categorical variables as frequencies. Comparisons of continuous variables between age-groups (65-69, 70-74, 75-79, 80-84, 85-89 and $90+$ ) were performed using Analysis of Variance; associations between categorical variables and age-groups were tested using the Pearson chi-squared test. Generalized estimating equations, with unstructured correlation matrix, were used to evaluate the associations between participants' lifestyle factors (i.e., frequency of current smoking habits, physical activity, level of adherence to Mediterranean diet) and cardiometabolic disorders (i.e., prevalence of hypertension, diabetes, hypercholesterolemia and obesity), as well as a cumulative score of the aforementioned morbidities, as a proxy of total CVD risk (range 0-4). Time series analysis, with lag 1, was used to predict trends of lifestyle characteristics (i.e., smoking habits, physical activity, socializing, alcohol consumption and adherence to Mediterranean diet) and prevalence of the aforementioned cardiometabolic disorders across participants' ageing process. Logistic regression models were applied to evaluate the association between prevalence of hypertension, hypercholesterolemia, diabetes, obesity, and the cardiometabolic risk factors (0-4) with various socio-demographic and lifestyle characteristics of the participants. Results are presented as Odds Ratios and 95\% confidence intervals. STATA version 15 (M. Psarros and Associates, Sparta, Greece) was used for all calculations.

\section{RESULTS}

\subsection{Cardiometabolic disorders, ageing and lifestyle factors}

Basic socio-demographic data, lifestyle and clinical characteristics of participants, by age group, are summarized in Table 1. The average number of friends was $5.0 \pm 5.8$ for older adults, while around $32 \%$ of older adults participated in social events. Current smokers reported the $15.4 \%$ of the participants, and physically active the $44 \%$. The level of adherence in the Mediterranean diet was moderate as the average score was $32.5 \pm 5.0$ (out of 55). Overall older adults visited health care services about $1.5 \pm 1.4$ and $1.2 \pm 1.1$ times per year during winter and summer respectively. The average number of cardiometabolic risk factors was $1.7 \pm 1.1$ for older adults, while the most prevalent disorder was hypertension (65\%), followed by hypercholesterolemia ( $49 \%)$, obesity (33\%) and diabetes mellitus (24\%).

\begin{tabular}{|c|c|c|c|c|c|c|c|}
\hline & $\begin{array}{c}65-69 y \\
(n=1171)\end{array}$ & $\begin{array}{l}70-74 y \\
(n=680)\end{array}$ & $\begin{array}{l}75-79 y \\
(n=630)\end{array}$ & $\begin{array}{l}80-84 y \\
(n=390)\end{array}$ & $\begin{array}{l}85-89 y \\
(n=173)\end{array}$ & $\begin{array}{l}\geq 90 y \\
(n=76)\end{array}$ & $\boldsymbol{p}$ for trend \\
\hline Male (\%) & 46 & 49 & 51 & 57 & 55 & 61 & 0.007 \\
\hline Living alone (\%yes) & 17 & 21 & 27 & 29 & 34 & 38 & $<0.001$ \\
\hline Participation in social events (\%yes) & 37 & 35 & 30 & 23 & 21 & 7.3 & $<0.001$ \\
\hline Number of friends & $5.1 \pm 5.8$ & $4.5 \pm 5.4$ & $5.2 \pm 7.1$ & $4.1 \pm 5.5$ & $2.8 \pm 2.9$ & $3.2 \pm 5.5$ & 0.01 \\
\hline Number of visits to healthcare services (winter) & $1.7 \pm 1.6$ & $1.1 \pm 1.1$ & $1.2 \pm 1.1$ & $1.3 \pm 1.2$ & $1.8 \pm 1.3$ & $1.8 \pm 1.0$ & $<0.001$ \\
\hline Number of visits to healthcare services (summer) & $1.4 \pm 1.2$ & $0.9 \pm 0.9$ & $1.0 \pm 0.9$ & $1.0 \pm 0.9$ & $1.4 \pm 1.0$ & $1.3 \pm 0.7$ & $<0.001$ \\
\hline $\begin{array}{l}\text { Access to healthcare services banned due to financial reasons } \\
\text { (\%) }\end{array}$ & 34 & 32 & 38 & 27 & 21 & 7 & 0.07 \\
\hline MedDietScore (0-55) & $33 \pm 4.8$ & $32.4 \pm 5.0$ & $32.4 \pm 4.9$ & $31.9 \pm 5.4$ & $32.5 \pm 5.2$ & $32.1 \pm 5.3$ & 0.009 \\
\hline Alcohol glasses / day & $0.66 \pm 0.85$ & $0.66 \pm 0.79$ & $0.52 \pm 0.75$ & $0.47 \pm 0.71$ & $0.46 \pm 0.66$ & $0.61 \pm 0.81$ & 0.003 \\
\hline Currently Smoking (\%yes) & 21 & 14 & 15 & 10 & 7 & 3 & $<0.001$ \\
\hline Adequate physical activity (\%yes) & 48 & 51 & 48 & 44 & 35 & 37 & 0.001 \\
\hline Obesity (\%yes) & 37 & 36 & 30 & 28 & 22 & 9.0 & $<0.001$ \\
\hline Diabetes (\%yes) & 22 & 29 & 27 & 23 & 22 & 16 & 0.003 \\
\hline Hypertension (\%yes) & 59 & 72 & 69 & 68 & 62 & 68 & $<0.001$ \\
\hline Hypercholesterolemia (\%yes) & 52 & 53 & 52 & 40 & 42 & 19 & $<0.001$ \\
\hline Cardiometabolic score (0-4) & $1.7 \pm 1.1$ & $1.9 \pm 1.1$ & $1.8 \pm 1.1$ & $1.6 \pm 1.1$ & $1.5 \pm 1.0$ & $1.2 \pm 0.9$ & $<0.001$ \\
\hline
\end{tabular}

Values are presented as number (\%) or mean \pm standard deviation.

A $0.7 \%$ decrease in prevalence of current smoking for every year increase in age was found (b per 1 year \pm SE: $-0.7 \% \pm 0.01, p<0.001)$. A decrease was also observed in the engagement of physical activities $(-0.7 \% \pm 2$, $p=0.001)$ and in the participation in social events $(-0.9 \% \pm 2, p<0.001)$. Moderate alcohol consumption increased with aging $(31.4 \% \pm 28 \%, p=0.008)$, whereas adherence to Mediterranean diet remained stable $(-1.5 \% \pm 1.2, p=0.9)$ with the MedDietScore derived being moderate across aging (average level of adherence was $28 \pm 5$ out of 55 , or $51 \%$ adherence to the ideal Mediterranean diet). 
With regards to cardiometabolic factors, prevalence of obesity $(-0.8 \% \pm 0.2, p<0.001)$ and hypercholesterolemia decreased across age-groups $(-0.9 \% \pm 0.2, p=0.001$, respectively), whereas no significant changes were found in the prevalence of diabetes $(-0.1 \% \pm 0.2, p=0.712)$ and hypertension $(0.1 \% \pm 0.2, p=0.514)$, across aging.

\subsection{Lifestyle habits and cardiometabolic disorders}

Further analysis (Table 2) of the studied lifestyle factors and the prevalence of cardiometabolic disorders, accounting for the region of residence (as a level), revealed that engagement in physical activities was associated with a lower prevalence of hypertension and obesity; adherence to the Mediterranean diet was associated with lower prevalence of hypertension, diabetes (and borderline associated with obesity), whereas smoking habit was favorably associated with obesity (only). By the exception of diabetes, increased age and male sex were associated with lower likelihood of having hypertension, hypercholesterolemia or obesity; while no association was observed as regards diabetes. No association was found between obesity and hypertension, hypercholesterolemia and diabetes (data not shown).

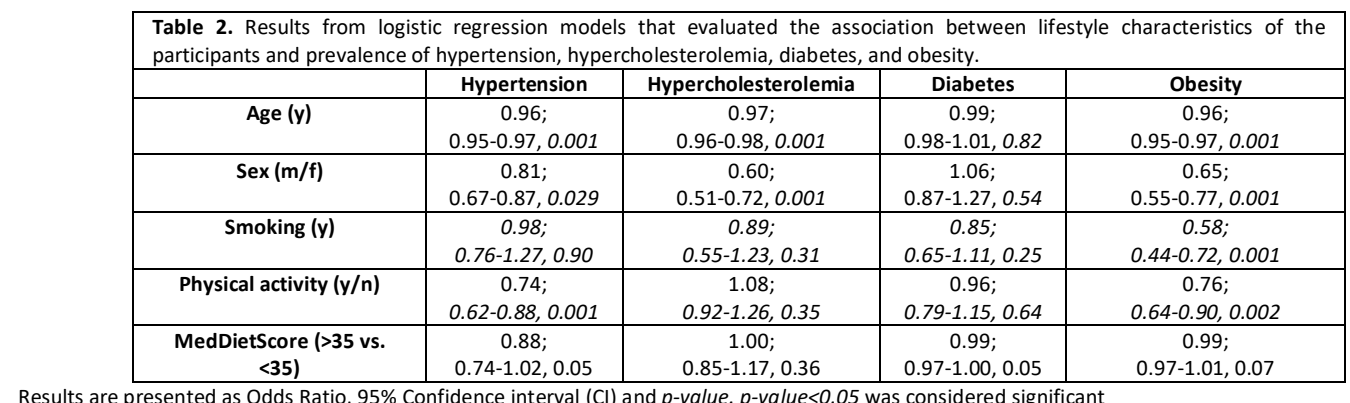

Moreover, sensitivity analyses stratified by rural vs. urban areas and by country (i.e., Greece, Cyprus, Malta, Italy and Turkey) were also conducted. As far as rural and urban areas were concerned, it was observed the same tendency in both rural and urban areas as the results reported in Table 2.

Moreover, when the analyses were stratified by country of residence, the results were also similar for the participants from Greece, Cyprus, Malta and Italy, but not for the Spanish islands, were no significant relationships were observed.

\subsection{Aging and socializing}

Age was positively associated with higher likelihood of living alone (odds ratio $1.05,95 \% \mathrm{Cl}$ : 1.03-1.06); similarly, an inverse correlation between age and number of friends was revealed $(r=-0.064, p=0.004)-$ no changes in the results when the analysis was stratified by gender or by region or area of residence were observed-.

\subsection{Aging and use of healthcare services}

An inverse association was found between increased age and number of visits to healthcare services during winter $(r=-0.014, p=0.009)$ as well as summer time $(r=-0.016, p<0.001)$. The odds of not visiting healthcare services due to financial reasons was reduced for each year increase in age (0.97, 95\% $\mathrm{Cl}$ : 0.95-0.99).

As before, no changes in the results were observed when the analysis was stratified by gender or by region or area of residence.

\subsection{Aging and cardiometabolic burden}

An inverse relationship was found between age of the participants and total cardiometabolic score $(b=-$ $0.01 \pm 0.05, p=0.007)$, meaning that older age was associated with lower cardio-metabolic burden. However, an additional trend analysis revealed that a quadratic (U-shape) function better characterized the association between age and total cardiometabolic risk ( $p$ for trend $<0.001)$ (Figure 1). No other significant trend was observed when individual cardiometabolic disorders were tested (all $p$ 's for trend $>0.5$ ). 
Figure 1. Trend analysis (quadratic function) of the association between age and average number of certain cardiometabolic risk factors that prevailed among the participants (i.e., hypertension, hypercholesterolemia, obesity and diabetes).

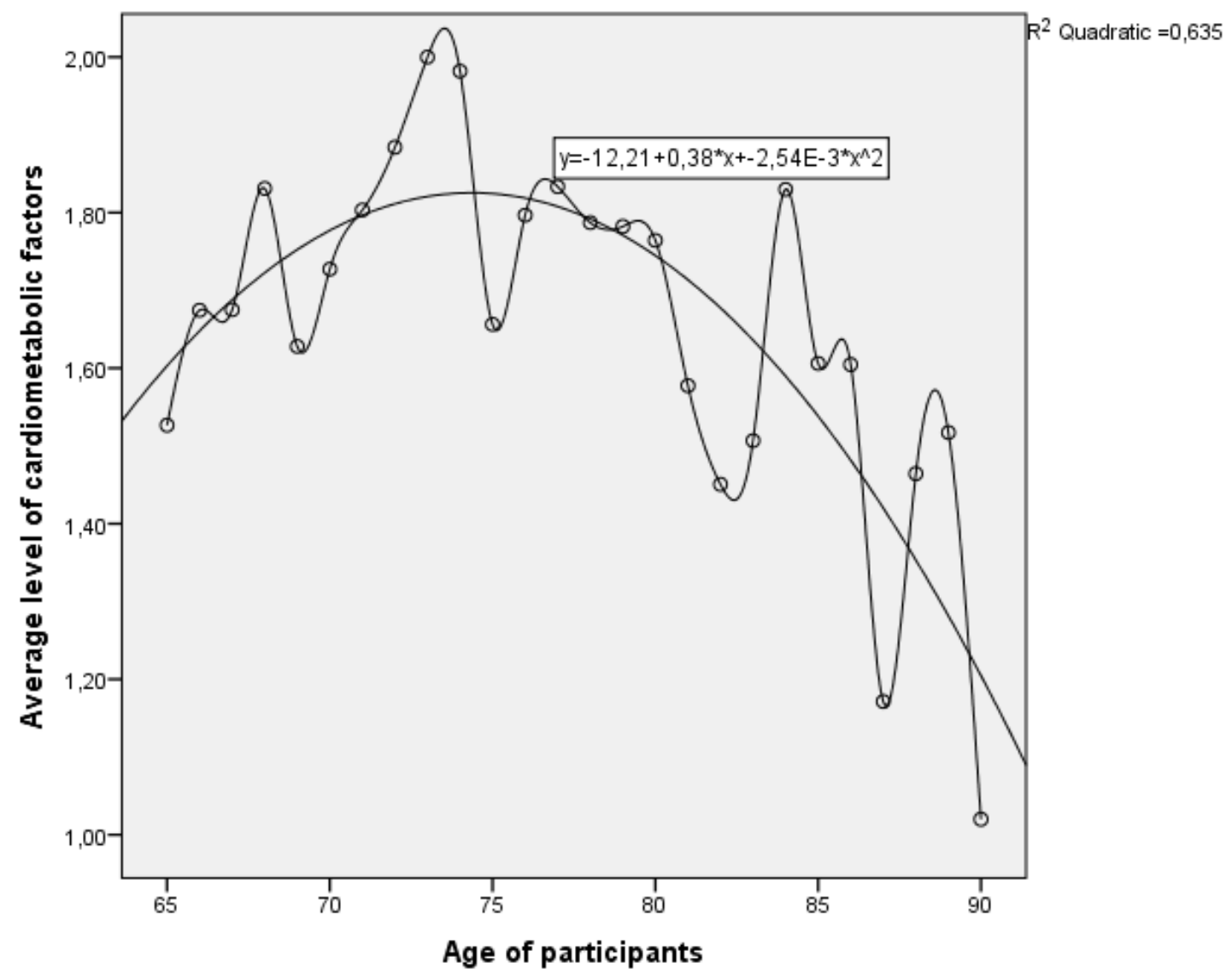

\section{DISCUSSION}

The aim of the present work was to evaluate the status of modifiable lifestyle risk factors related to cardiovascular disease (CVD) among older adults living in the Mediterranean area, across their course of ageing. Secondarily to evaluate the prevalence of cardiometabolic disorders across various age groups. Linear and nonlinear trends of certain lifestyle behaviors and cardiometabolic risk factors prevalence, during the course of ageing, were revealed. The present work revealed that smoking habit decreases with ageing, whereas dietary behaviors and particularly adherence to the Mediterranean diet was almost constant, but moderate. As expected engagement in physical activities, at least in moderation, reduced as the years passed for both men and women. Participation in social life events reduced across ageing, whereas, older adults tended to live alone as they aged and to have less friends. Of interest was that the access to healthcare services was banned due to financial reasons, and this was more evident among younger participants (Table 2). As regards CVD clinical risk factors, all four studied here, i.e., hypertension, hypercholesterolemia, diabetes and obesity showed reducing trends across age groups (Table 2), with older adults over 90 years old having the lowest CVD burden. However, at this point it should be noted though that the fact that the oldest old had less cardiometabolic factors and, also presented healthier lifestyles, could be attributed to Darwin's "natural selection" theory (Darwin, 1859). In brief, people with morbidities have greater possibility not being alive and not being selected during the sampling, explaining the reverse relation between age and cardio-metabolic load. Despite the limitations of the present work due to its observational design, the reported findings deserves further attention, as they are one of the first attempts to present trajectories of healthy aging and evaluate them in terms of lifestyle behaviors, in this region.

Several studies have reported similar to the present works' findings regarding lifestyle factors and their ageassociated declines in physical and cognitive function, as well as overall health status. Body weight within the normal range, not smoking and being physically active are among the most documented healthy behaviors for preventing and managing diseases among older adults (Britton, Shipley, Singh-Manoux, \& Marmot, 2008; Franklin \& Tate, 2009). As regards dietary habits, a healthy dietary pattern, like the Mediterranean diet, has long been associated with better health and longevity (Georgousopoulou et al., 2017). A recent study conducted in Germany also found that the prevalence of over limited alcohol consumption, the prevalence of current smoking and physical inactivity showed a downward trend as regards aging (Völzke et al., 2015). Similarly, Bullo et al., assessing the relationship between healthy lifestyle behaviors and the odds of prevalent obesity for a 
Mediterranean elderly population at high cardiovascular risk, found that moderate alcohol consumption, adherence to the Mediterranean diet, smoking cessation and daily physical activity can significantly benefit older adults (Bulló et al., 2011). In addition, results from a study conducted in an older Italian island population from the same region (i.e., the Mediterranean healthy Eating, Aging and Lifestyle (MEAL) study cohort), in relation to lifestyle habits, reported a decline in adherence to the Mediterranean dietary pattern over the years, whereas, higher adherence was associated with education, non-smoking and physical activity and inversely with high occupational status, underlying the triggering role social determinants on healthy aging. Moreover, the overall prevalence of obesity was $18 \%$, while $58 \%$ of men and $45 \%$ of women were hypertensive, $11 \%$ of men and $5 \%$ of women were diabetic, and $15 \%$ of men and $21 \%$ of women had dyslipidemia, rates that were comparable to the MEDIS study findings. Moreover, better cardiometabolic status was observed among high physical active and non-smoker individuals, with higher social status (Mistretta et al., 2017); findings similar to the ones reported in the present study.

The results of the MEDIS study also highlighted significant declines in certain lifestyle, and social behaviors and clinical characteristics, among the older old adults, and particularly those over 90 or 95 years old, such as smoking habits, hypercholesterolemia, obesity and diabetes, that worth a head-to-head comparison with other similar nonagenarians studies. In a study investigating the prevalence of obesity in Chinese nonagenarians and centenarians, it was observed that the risk of activities of daily and instrumental living activities disabilities was higher for women with both extremely low and high BMls, but this pattern was not found in men (Yang et al., 2014). In the present work no association was found between obesity and CVD co-morbidities, hypertension, hypercholesterolemia and diabetes, or physical activity status, whereas a significant decline in obesity rates was revealed across age-groups. Concerning the presence of diabetes, an analysis of the Santfeliu study in China found that only 2 out of the 23 examined centenarians had diabetes (Formiga, Ferrer, Pérez-Castejon, \& Pujol, 2007), a fact that it is line with the lower prevalence among older old adults of diabetes in the present study too.

The present study also revealed that there was an inverse association between age and health service utilization. The use of healthcare services vary by health system, and may also vary by sex, age, social class, and other social-related factors (Jacobs et al., 2012). It should be noted though that healthcare services may also vary within countries and they are depended on the available health services on each region. People living in less densely populated regions, i.e., insular areas or isolated villages, may not have the same opportunities or facilities to access health care services with those living in mainland (Papanikolaou et al., 2011). It is also a fact that the number of hospitals in rural or remote areas are disproportionately smaller than in urban areas, while healthcare has severely affected by the recent economic crisis (Deloitte, 2017). This difference might be explained by divergences in healthy ageing for those living in Mediterranean regions, since previous studies indicated that the oldest old people in countries like Greece have a quite good health status and that their aging process is not necessarily accompanied by disease and disability (Darviri et al., 2008).

Limitations

This is a cross-sectional survey that limits the possibility for causal relationships. It could be suggested that the differences reported between the different age groups are a result of other factors, such as the divergence in birth cohorts, differences between generations and selective mortality. Indeed, literature evidence indicates that different birth cohorts differ by far regarding their healthy lifestyle characteristics and the adoption of selfharming behaviors. For example, in the United States, a significant increase in the frequency of smoking had been reported for the cohort returning from Europe after the World War II (Brandt, 2007). In line with the general differences in healthy lifestyle factors found in the literature, it could be supported that the differences reported in that study are also subjected to the limitation of different health behaviors based on different generations. Moreover, there was not a systematic sampling scheme that could guarantee representativeness; however the large number of islands involved, as well as the attempts made to include participants from various villages of each island may reduce the lack of representativeness of the total older adult population. Moreover, people living in the Mediterranean area are characterized by a difference in healthy lifestyle factors compared to those living elsewhere, such as the local traditional diet (Trichopoulou, 2001), which might modify the effect of other disease-related factors (Vardavas, Papadaki, Saris, \& Kafatos, 2009). Furthermore, the findings of this study might have low generalizability to other regions, but could also constitute the basis for similar investigations and comparisons. Selective mortality, meaning a difference in the characteristics between those achieving longevity and those not (Aschengran \& Seage, 2014), is another limitation of the present study. Due to the complex relationships between healthy lifestyle and disease related factors, it could be supported that there is a selective mortality limitation attributed to a variety of factors which could have a significant effect. For example, sleep is an important behavioral parameter associated with the onset of other chronic health conditions, as well as with human longevity (Georgousopoulou et al., 2017).

Conclusions

Life expectancy has increased, however, gaps in the understanding of factors affecting longevity and ageing still remain. Lifestyle behaviors, like smoking cessation, healthy eating habits and moderate alcohol consumption should be adopted from younger ages, whereas physical activity and socializing should be promoted in order to achieve healthy ageing (Pruchno \& Wilson-Genderson, 2012). Health authorities and other stakeholders should establish healthy ageing strategies and interventions focused on awareness and education, as well as on healthy public policy and legislation, taking full account of all the components of health, including 
lifestyle. Since older people have different health requirements (Boettger, Bergman, Jenewein, \& Boettger, 2016; Branca et al., 2009), and age with different ways as this as well as other works reported, the presented findings are of major importance for the stakeholders in order to promote healthy ageing, through different types of lifestyle interventions, targeting the actual needs of older adults. However, policies and strategies promoting older adults' health need to have realistic objectives, with specific actions in order to prolong the autonomy and independence of older people.

\section{ACKNOWLEDGEMENTS}

We are, particularly, grateful to the men and women from the islands of Lesvos, Cyprus, Crete, Cephalonia, Corfu, Zakynthos, Syros, Tinos, Naxos, Salamina, Samothraki, Lemnos, Ikaria, Kassos, Rhodes, Karpathos, Mani, Malta, Mallorca and Minorca, Sardinia and Gökçeada, who participated in this research. The MEDIS study group is: M. Tornaritis, A. Polystipioti, M. Economou, (field investigators from Cyprus), A. Zeimbekis, K. Gelastopoulou, I. Vlachou (field investigator from Lesvos), I. Tsiligianni, M. Antonopoulou, N. Tsakountakis, K. Makri (field investigators from Crete), E. Niforatou, V. Alpentzou, M. Voutsadaki, M. Galiatsatos (field investigators from Cephalonia), K. Voutsa, E. Lioliou, M. Miheli (field investigator from Corfu), S. Tyrovolas, G. Pounis, A. Katsarou, E. Papavenetiou, E. Apostolidou, G. Papavassiliou, P. Stravopodis (field investigators from Zakynthos), E. Tourloukis, V. Bountziouka, A. Aggelopoulou, K. Kaldaridou, E. Qira, (field investigators from Syros and Naxos), D. Tyrovola (field investigator from Kassos), I. Protopappa (field investigator from Ikaria), C. Prekas, O. Blaserou, K.D. Balafouti (field investigators from Salamina), S. Ioakeimidi (field investigators from Rhodes and Karpathos), A. Foscolou (field investigator from Tinos), A. Mariolis, E. Petropoulou, A. Kalogerakou, K. Kalogerakou (field investigators from Mani), S. Piscopo (field investigators from Malta), J.A. Tur (field investigators from Mallorca and Menorca), G. Valacchi, B. Nanou (field investigators from Sardinia and Sicily), A. Foscolou, E. Paka, P. Drepanidis (field investigators from Gökçeada) for their substantial assistance in the enrolment of the participants.

\section{Conflict of interest}

None of the authors have any conflict of interest related to this project.

Funding

The Study was funded by Research grants from the Hellenic Heart Foundation, the Graduate Program of the Department of Nutrition \& Dietetics, Harokopio University and the Rutgers University, NJ, USA (GA \#5884). Stefanos Tyrovolas was supported by the Foundation for Education and European Culture (IPEP), the Sara Borrell postdoctoral program (reference no. CD15/00019 fromthe Instituto de Salud Carlos III (ISCIII - Spain) and the Fondos Europeo de Desarrollo Regional (FEDER). DemosthenesPanagiotakos and Stefano Tyrovolashave been funded for ATHLOS project to study trajectories of healthy aging (European Union's Horizon 2020 research and innovation program, grant agreement No 635316). Josep A. Tur was funded by grants PI11/01791, CIBERobn CB12/03/30038, and CAIB/EU 35/2001.

\section{References}

Alberti, K. G., \& Zimmet, P. Z. (1998). Definition, diagnosis and classification of diabetes mellitus and its complications. Part 1: diagnosis and classification of diabetes mellitus provisional report of a WHO consultation. Diabetic Medicine: A Journal of the British Diabetic Association, 15(7), 539-553.

Aschengran, A., \& Seage, G. (2014). Essentials of Epidemiology in Public Health (Third). Jones \& Barlett Learning.

Bach-Faig, A., Berry, E. M., Lairon, D., Reguant, J., Trichopoulou, A., Dernini, S., ... Mediterranean Diet Foundation Expert Group. (2011). Mediterranean diet pyramid today. Science and cultural updates. Public Health Nutrition, 14(12A), 2274-2284.

Boettger, S., Bergman, M., Jenewein, J., \& Boettger, S. (2016). Advanced age and decisional capacity: The effect of age on the ability to make health care decisions. Archives of Gerontology and Geriatrics, 66, 211-217.

Branca, S., Bennati, E., Ferlito, L., Spallina, G., Cardillo, E., Malaguarnera, M., ... IMUSCE. (2009). The health-care in the extreme longevity. Archives of Gerontology and Geriatrics, 49(1), 32-34.

Brandt, A. (2007). The Cigarette Century: The Rise, Fall and Deadly Persistence of the Product That Defined America. New York: Basic Books.

Britton, A., Shipley, M., Singh-Manoux, A., \& Marmot, M. G. (2008). Successful aging: the contribution of early-life and midlife risk factors. Journal of the American Geriatrics Society, 56(6), 1098-1105.

Bulló, M., Garcia-Aloy, M., Martínez-González, M. A., Corella, D., Fernández-Ballart, J. D., Fiol, M., ... Salas-Salvadó, J. (2011). Association between a healthy lifestyle and general obesity and abdominal obesity in an elderly population at high cardiovascular risk. Preventive Medicine, 53(3), 155-161.

Chrysohoou, C., Pitsavos, C., Lazaros, G., Skoumas, J., Tousoulis, D., Stefanadis, C., \& Ikaria Study Investigators. (2016). Determinants of All-Cause Mortality and Incidence of Cardiovascular Disease (2009 to 2013) in Older Adults: The Ikaria Study of the Blue Zones. Angiology, 67(6), 541-548.

Courtin, E., Jemiai, N., \& Mossialos, E. (2014). Mapping support policies for informal carers across the European Union. Health Policy (Amsterdam, Netherlands), 118(1), 84-94.

Darviri, C., Demakakos, P., Charizani, F., Tigani, X., Tsiou, C., Chalamandaris, A. G., ... Chliaoutakis, J. (2008). Assessment of the health status of Greek centenarians. Archives of Gerontology and Geriatrics, 46(1), 67-78.

Darwin, C. (1859) On the Origin of Species by Means of Natural Selection, or the Preservation of Favoured Races in the Struggle for Life (3rd ed.). London: John Murray.

Deloitte. (2017) Healthcare in Greece. Overview and Trends. Retrieved from https://www2.deloitte.com/content/dam/Deloitte/gr/Documents/life-sciences-healthcare/gr healthcare in greece noexp.pdf.

Expert Panel on Detection, Evaluation, and Treatment of High Blood Cholesterol in Adults. (2001). Executive Summary of The Third Report of The National Cholesterol Education Program (NCEP) Expert Panel on Detection, Evaluation, And Treatment of High Blood Cholesterol In Adults (Adult Treatment Panel III). JAMA, 285(19), 2486-2497.

Formiga, F., Ferrer, A., Pérez-Castejon, J. M., \& Pujol, R. (2007). Community-dwelling nondisabled nonagenarians: two-year follow-up: the NonaSantfeliu Study. Journal of the American Geriatrics Society, 55(5), 801-803.

Franklin, N., \& Tate, C. (2009). Lifestyle and Successful Aging: An Overview, 3(1), 6-11. 
Georgousopoulou, E. N., Mellor, D. D., Naumovski, N., Polychronopoulos, E., Tyrovolas, S., Piscopo, S., ... MEDIS study group. (2017). Mediterranean lifestyle and cardiovascular disease prevention. Cardiovascular Diagnosis and Therapy, 7(Suppl 1), S39-S47.

He, W., Goodkind, D., \& Kowal, P. (2016). An Aging Wold: 2015. International Population Reports.

Jacobs, J. M., Maaravi, Y., Cohen, A., Bursztyn, M., Ein-Mor, E., \& Stessman, J. (2012). Changing profile of health and function from age 70 to 85 years. Gerontology, 58(4), 313-321.

Mancia, G., Fagard, R., Narkiewicz, K., Redón, J., Zanchetti, A., Böhm, M., ... Task Force Members. (2013). 2013 ESH/ESC Guidelines for the management of arterial hypertension: the Task Force for the management of arterial hypertension of the European Society of Hypertension (ESH) and of the European Society of Cardiology (ESC). Journal of Hypertension, 31(7), 1281-1357.

Mistretta, A., Marventano, S., Platania, A., Godos, J., Galvano, F., \& Grosso, G. (2017). Metabolic profile of the Mediterranean healthy Eating, Lifestyle and Aging (MEAL) study cohort. Mediterranean Journal of Nutrition and Metabolism, 10(2), $131-140$.

Panagiotakos, D. B., Pitsavos, C., \& Stefanadis, C. (2006). Dietary patterns: a Mediterranean diet score and its relation to clinical and biological markers of cardiovascular disease risk. Nutrition, Metabolism, and Cardiovascular Diseases: NMCD, 16(8), 559568.

Papathanasiou, G., Georgoudis, G., Papandreou, M., Spyropoulos, P., Georgakopoulos, D., Kalfakakou, V., \& Evangelou, A. (2009). Reliability measures of the short International Physical Activity Questionnaire (IPAQ) in Greek young adults. Hellenic Journal of Cardiology: HJC = Hellenike Kardiologike Epitheorese, 50(4), 283-294.

Papanikolaou, V., Voskaki, A., Nearchou, A., Papadopoulos, Z., Roumelioti, A. (2011). Health inequalities for women living in rural regions: the prefecture of Xanthi, Greece. Health Care for Women International, 32(7), 613-631.

Passarino, G., De Rango, F., \& Montesanto, A. (2016). Human longevity: Genetics or Lifestyle? It takes two to tango. Immunity \& Ageing: I \& $A, 13,12$

Pruchno, R., \& Wilson-Genderson, M. (2012). Adherence to clusters of health behaviors and successful aging. Journal of Aging and Health, 24(8), 1279-1297.

Shadyab, A. H., \& LaCroix, A. Z. (2015). Genetic factors associated with longevity: a review of recent findings. Ageing Research Reviews, $19,1-7$.

Tosato, M., Zamboni, V., Ferrini, A., \& Cesari, M. (2007). The aging process and potential interventions to extend life expectancy. Clinical Interventions in Aging, 2(3), 401-412.

Trichopoulou, A. (2001). Mediterranean diet: the past and the present. Nutrition, Metabolism, and Cardiovascular Diseases: NMCD, 11(4 Suppl), 1-4.

Tyrovolas, S., Chalkias, C., Morena, M., Tsiligianni, I., Zeimbekis, A., Gotsis, E., ... Panagiotakos, D. (2011). Health care access and prevalence of the metabolic syndrome among elders living in high-altitude areas of the Mediterranean islands: the MEDIS study. The Review of Diabetic Studies: RDS, 8(4), 468-476.

Tyrovolas, S., Haro, J. M., Mariolis, A., Piscopo, S., Valacchi, G., Tsakountakis, N., ... Panagiotakos, D. (2014). Successful aging, dietary habits and health status of elderly individuals: a k-dimensional approach within the multi-national MEDIS study. Experimental Gerontology, 60, 57-63.

Tyrovolas, S., Pounis, G., Bountziouka, V., Polychronopoulos, E., \& Panagiotakos, D. B. (2010). Repeatability and validation of a short, semi-quantitative food frequency questionnaire designed for older adults living in Mediterranean areas: the MEDIS-FFQ. Journal of Nutrition for the Elderly, 29(3), 311-324.

Tyrovolas, S., Zeimbekis, A., Bountziouka, V., Voutsa, K., Pounis, G., Papoutsou, S., ... Panagiotakos, D. B. (2009). Factors Associated with the Prevalence of Diabetes Mellitus Among Elderly Men and Women Living in Mediterranean Islands: The MEDIS Study. The Review of Diabetic Studies: RDS, 6(1), 54-63.

Van De Kaa, D. J. (1987). Europe's second demographic transition. Population Bulletin, 42(1), 1-59.

Vardavas, C. I., Papadaki, A., Saris, W. H. M., \& Kafatos, A. G. (2009). Does adherence to the Mediterranean diet modify the impact of smoking on health? Public Health, 123(6), 459-460; author reply 460.

Völzke, H., Ittermann, T., Schmidt, C. O., Baumeister, S. E., Schipf, S., Alte, D., ... Hoffmann, W. (2015). Prevalence trends in lifestylerelated risk factors. Deutsches Arzteblatt International, 112(11), 185-192.

WHO. (n.d.). Management of substance abuse. Retrieved from http://www.who.int/substance abuse/research tools/translation/en/.

Yang, M., Hao, Q., Luo, L., Ding, X., Wu, H., Zhang, Y., \& Dong, B. (2014). Body mass index and disability in Chinese nonagenarians and centenarians. Journal of the American Medical Directors Association, 15(4), 303.e1-6. 